\title{
Patterns of Family Breeding Relationship with the Behavior of Violence at Students of the Secondary Stage
}

\author{
Ibarhim Bajes Maali ${ }^{1}$ \\ ${ }^{1}$ Dean of Faculty of Educational Sciences, The World Islamic Sciences and Educational University, Jordan \\ Correspondence: Ibarhim Bajes Maali. E-mail: maliibraheem@yahoo.com
}

Received: June 2, 2018

Accepted: August 22, 2018

Online Published: August 31, 2018

doi:10.5539/ass.v14n9p91

URL: https://doi.org/10.5539/ass.v14n9p91

\begin{abstract}
The study aimed at disclosing the relationship of family breeding with the behavior of violence at students of the secondary stage. The sample of study consisted of (311) male and female students had been chosen randomly from the community of study. To achieve the objectives of study, a scale of family breeding styles had been prepared, and have three dimensions, they are: the democratic style, the predominant style and the abandonment style.

Results of study indicated that predominant style came in the first rank, the abandonment style in the second rank, and the democratic in the last rank. Results disclosed the effect of sex for the interest of males in the differences and behavior of violence, and non-existence of differences ascribed to the effect of the grade, and existence of positive connective relationship statistically significant between the behavior of the violence and the predominant style.
\end{abstract}

Keywords: family breeding, violence

\section{Introduction}

Violence is considered one of the emotional problems that science concerned about in the last period, characterized as problem became considered basic in ma's life of its different sides. Researchers had differed in its definition. Cormier defined violence as a strong feeling of un satisfaction. And it is aimed at a person, or certain thing, that leads to occurring an emotional state causes herm and anxiety to the intended person, and the aim of this emotionalism, is protecting oneself from exposing to such harm in the future,

Namka (2012) distinguishes two forms of violence, they are:

1. Health-violence: it is a logical emotional reaction, pliable to bodily harm, and mistreatment to which the individual is exposed, and attempts through him to protect himself.

2. Unhealthy violence: it is the violence resulted in ideas, and negative feeling, and that leans to unaccepted reasons to justify violence.

Crossman (2011) specified external appearance of violence with the following:

1. Temperamental change affects the individual as a whole, and not in a certain part of the body.

2. External changes appear through the change that emerges on the individual's behavior.

3. Internal changes their effects appear on the body as an increase of heart-beats.

4. Violence has an expressive appearance appears through the movement of the body and its readiness to fighting, such as the change of voice intonation.

Many theories had appeared in explaining violence, for the biologic theory indicates that violence has its biologic causes, and can be hereditary (Clayton \& Tacker, 2010). But the cognitive theory indicates that irrational ideas are the reason of disorder and violence (wreikat, 2010). But the behavioral theory views that violence is learning behavior, as behavior is reinforced, then generalization is done (Corey, 2015), but the Analyzing Theory Views that violence is one of the most important appearances of the aggressive instinct at human, and violence needs satisfaction (Amer, 2014).

Also sex has a role in expressing violence, for males are move expressing their violence than females, who tend to suppress their violence, and never express it bodily, but verbally, for girls are move able to express their 
emotions by speaking (Kathiann, 2013).

Feshnbach (2014) mentions that females differ from males in the sources that cause violence, and in the method of expressing violence. It was found that decrease of paternal satisfaction, its effect be as a source of violence at females greater than it at the males.

Rubin \& Chung (2016) view that techniques of family breeding from a cognitive start indicates to the parent's beliefs about the good fatherhood and sons' breeding behavior of parents towards sons, and quality of the relationship between the child, father and mother.

Hockenburg and Hockenbur (2014) had indicated that psychologists divided the family techniques into numerous types, they are:

Domination technique:

It is meant prevention, permanent rejection and constant for all demands of the individual, severity and strictness in interaction with the sons, using techniques of prohibition, command, punishment, and deprivation (Naser Allah, 2014).

Lenient technique:

It is represented in leaving the individual in achieving his wishes in accordance with what pleases him and continuous response to his demands as a problem of non-adaptation, and feeling with frustration (Al-Rashdan, 2015).

Democratic technique:

Thigs between the parents and sons move at a cooperative form, through dialogue and continuous consultation with the sons by following the persuasive technique and respect the opinion and the other opinion (O'beidat, 2011).

\subsection{Problem of Study and Its Significance}

The parents employing of effective techniques leads to wished results, but the non-effective techniques lead to behavioral problems like anxiety and violence.

Violence is one of the most complicated human emotions, and it is a learned behavior, acquired by the individual from stages of childhood through techniques of family breeding, and individuals differ in expression about violence due to ideas, feelings, and due to the age and the technique of family breeding he was exposed to. And due to what preceded and the researcher's perception with the significance of violence behavior and its reflection on the sons' behavior at a negative form, and also the significance of parental breeding techniques in affecting the level of violence behavior, pushed him to prepare the present study to disclose the relationship of the family breeding with violence behavior at students of the secondary stage.

The problem of the present study comes through answering the following questions:

The first question: what is the level of violence behavior at students of secondary stage?

The second question: what are the prevailing family breeding techniques from the point of view of students of the secondary stage?

The third question: are there differences statistically significant at the level of significance $(\alpha \leq 0.05)$ in the level of violence behavior at students of the preparatory stage ascribed to the variables of sex and class?

The fourth question: is there a connective relationship between the technique of family breeding and violence behavior at students of the secondary stage?

\subsection{Definition of Study Terms}

Violence: represents the general reaction of the frustration he is exposed to, because of mistreatment, and it is a strong feeling of non-satisfaction, aimed at a certain person, or a certain thing and leads to causing harm, (Cormier, 2015). It is procedurally defined for goals of this study at the degree obtained by the individual on items of violence scale used in this study.

Family breeding techniques: they are the educational techniques followed by parents with their sons across different stage of their growth, and affect their personalities negatively or positively (Al-Ghirbawi, 2013). And it is procedurally defined at the degree obtained by the student on the scale of family breeding techniques used in this study. 


\subsection{Previous Studies}

Al-Ameer study (2010) aimed at recognizing patterns of social breeding in the family and school in Jordan, and the relationship of that with studying excellence. The sample of study amounted to (600) male and female students. Results of study indicated that there is a connective relationship between the prevailing social breeding patterns in the family, and obtainment of excellent students, and also existence of a connective relationship between the prevailing social breeding pattern in the family and sex.

(Coles, 2012) did a study on the relationship between the family breeding and expressing violence, among males on purpose of recognizing traits of the personality and the level of oneself concept. The sample of study consisted of (99) male and female students. Their ages amount (13-18) years. The list of expressing violence had been used, and results indicated that the level of anger among males is high and there is a relationship between violence and the concept of oneself, but this relationship decreases together with the existence of family control.

(Johnes \& Jolly, 2014) study, who did a study, entitled "Is there a relationship between the family breeding and violence at adolescents? By comparison between (163) male and female adolescents ( 73 males \& 90 females) from sons of the divorced people and sons of normal families of the secondary stage at six schools. Scale of violence had been applied. Result indicated to existence of differences with statistical significance between both groups ascribed to the effect of family breeding for the normal families, appeared through violence, and the level of paternal support to sons, and essential differences did not appear between both sexes.

(Duriez, Soenens \& Vansteenkiste, 2015) wrote a study aimed at recognizing sharing of parents' encouragement in building objective and dimensions of family treatment pattern. The sample of study consisted of (956) students from the secondary stage. Results indicated that the democratic technique did not connect with aiming at social domination, but the pattern of dictatorial treatment had connected at a direct form at the level of social domination.

(Lopez, 2016) prepared a study aimed at disclosing the parental treatment positively or negatively with muting behavior at students of the secondary stage. The study consisted of (349) students. Results of study indicated that there is a positive connective relationship between the behavior of democratic breeding pattern and the good social behavior, results of study also indicated that the pattern of tyrant breeding shared in developing the muting, disobedience and violence behavior by students.

(Liem, Cavell, \& Lustig, 2016) did a study aimed at recognizing the parental breeding techniques and their effect on the psychological health and disclosing the continuance of parental breeding techniques effect through adolescence stage in what relates with symptoms of sadness. The sample of study consisted of (1143) students of the upper stage students and (128) students. Results of study indicated to existence of connective relationship between the techniques of parental breeding during adolescence and development of sadness symptoms.

\section{Method and Procedures}

\subsection{Community of Study and the Sample}

The community of study consisted of all students of the tenth secondary and eleventh secondary grades at the public schools, amounting to (1560) male and female students. The sample of study had been chosen at a random method, where their number amounted to (311) male and female students.

\subsection{Instruments of Study}

Firstly, scale of violence: they did prepare the scale for it consisted of (19) items, and had assured of indications of the scale validity through showing it to (10) of those with specialization. The researcher did extract the reliability of the scale by the method of test-retest, where the reliability coefficient $(0.85)$ through applying it on a sample out of the sample of study amounting to (35) male and female students.

The scale is corrected by using fivefold gradual, it amounts between very great degree (5), great (4), medium (3), few (2), and very few (1) at answering the positive items, and these values are turned to the opposite at answering the negative items. And to explain the estimations of violence behavior level, the performance had been divided on the items of the scale into three levels, in accordance with the extent of class amounting to (1-5) as follows:

1. The low level: $(1-2.33)$ degrees.

2. The medium level: $(2.34-3.67)$ degrees.

3. The high level, $(3.68-5)$ degrees.

Secondly: scale of family breeding techniques 
The scale consisted of (45) items, divided into two models, the father model and the mother model, and each model consisted of three techniques: the democratic technique, the tyrant technique, and the lenient technique, where the answer amounts to (two degrees) band (and degree) between yes and no. and for the purposes of this study, the researcher did the validity of content for the scale, where it had been shown to a number of specialized arbitrators, and the researcher did extract the reliability coefficient to the scale too by using Cronbach Alpha equation, or the value of reliability amounted to (0.90) through applying it on a sample consisted of (30) male and female students from outside the study.

\subsection{Designing the Study and Statistical Analysis}

Variables of study:

Independent variable: techniques of family breading with all their types: the democratic, the tyrant, and the lenient variable.

Sex: male, female.

Grade: tenth, eleventh.

Subordinate variable: violence and its levels (high, medium, and low).

\section{Results}

The first question in the study "what is the level of violence behavior at students of the secondary stage?

The arithmetic means and standard deviations to the level of violence at students of the secondary stage.

Table 1.

\begin{tabular}{|c|c|c|c|c|}
\hline $\begin{array}{c}\text { Item } \\
\text { organizing }\end{array}$ & Items & $\begin{array}{l}\text { Arithmetic } \\
\text { Average }\end{array}$ & $\begin{array}{l}\text { Standard } \\
\text { deviation }\end{array}$ & Degree \\
\hline 1. & I say to myself "No benefit of violence" & 4.55 & 1.5 & high \\
\hline 2. & I become nervous, I revolt and threaten & 4.19 & 1.11 & high \\
\hline 3. & I throw, or break things & 4.09 & 1.03 & high \\
\hline 4. & The weak person is the one who dominates violence & 4.06 & 1.21 & high \\
\hline 5. & I feel quivering in my voice & 3.99 & 1.200 & high \\
\hline 6. & I can deal with stands at a sober way & 3.97 & 0.99 & high \\
\hline 7. & I regret and tell the other person that I am excited & 3.95 & 1.23 & high \\
\hline 8. & I think If I give a little we can negotiate & 3.93 & 1.07 & high \\
\hline 9. & I count to the number ten & 3.92 & 1.12 & high \\
\hline 10. & $\begin{array}{l}\text { I think of the problems that can occur if I lost } \\
\text { domination on myself }\end{array}$ & 3.83 & 1.21 & high \\
\hline 11. & I say or scream that I am violent & 3.83 & 1.21 & high \\
\hline 12. & I try to understand the person who excited my violence & 3.79 & 1.23 & high \\
\hline 13. & I attack the one who excited my violence & 3.75 & 1.26 & high \\
\hline 14. & I ask God's forgiveness & 3.75 & 1.26 & high \\
\hline 15. & I trust my ability to control my violence & 3.73 & 1.26 & high \\
\hline 16. & I ask God to grant me patience to deal with the stand & 3.66 & 1.31 & medium \\
\hline 17. & I am not obliged to behave violently as others & 3.59 & 1.14 & medium \\
\hline 18. & I try to calm myself & 3.46 & 1.41 & medium \\
\hline 19. & He breathed deeply and relaxed & 2.40 & 1.52 & medium \\
\hline 20. & Violence behavior as a whole & 3.81 & 0.64 & high \\
\hline
\end{tabular}

Table 1 clears that the arithmetic mean of violence behavior amounted to (3.81), the thing that violence behavior at individuals of the sample came high, and the arithmetic means amounted (2.40 - 4.55), for the item No. (13) That words "I attack the one who excited my violence" came in the first rank at an arithmetic mean (4.55) followed by the item No. (18) That words "I try to calm myself" at an arithmetic mean amounted (4.19), followed, in the third item, by the item No. (12) Words "I try understand the person who excited my violence" at an arithmetic mean (4.09) meanwhile the item No. (9) it word "I count to the number ten" came in the last rank 
at an arithmetic mean (2.28)

The second question: what are the prevailing family breeding techniques from students of the secondary stage point of view?

The arithmetic means and standard deviations had been extracted for the techniques of the family breeding, Table 2 Clear that.

Arithmetic means and standard deviations for techniques of the prevailing family breeding from the point of view of students of the secondary stage dissentingly organized due to the arithmetic means.

Table 2.

\begin{tabular}{cccc}
\hline No. & Technique & Arithmetic Mean & Standard Deviation \\
\hline 1. & Tyrant & 0.75 & 0.24 \\
2. & Lenient & 0.26 & 0.20 \\
3. & Democratic & 0.23 & 0.20 \\
\hline
\end{tabular}

It is clear from Table 2 that arithmetic means for techniques of the family breeding had amounted $(0.23-0.75)$, and the democratic technique came at the highest arithmetic mean amounted (0.75), came the lenient technique in the second rank at an arithmetic mean (0.26), meanwhile came the tyrant technique in the last rank and at the lowest arithmetic mean (0.23).

The third question: "are there differences statistically significant exist at the level of significance $(\alpha \leq 0.05)$ at the level of violence behavior ascribed to both variables of sex and class?"

The arithmetic means and standard deviations for the level of violence behavior, and the Table 3 Clears that.

Table 3. Arithmetic means and standard deviations for the level of violence behavior at students of the secondary stage due to both variables of sex and class

\begin{tabular}{cccccc}
\hline $\begin{array}{c}\text { Source of } \\
\text { variation }\end{array}$ & $\begin{array}{c}\text { Total of } \\
\text { squares }\end{array}$ & $\begin{array}{c}\text { Degrees of } \\
\text { Freedom }\end{array}$ & $\begin{array}{c}\text { Average of } \\
\text { squares }\end{array}$ & $\begin{array}{c}\text { F. } \\
\text { value }\end{array}$ & $\begin{array}{c}\text { Statistical } \\
\text { significance }\end{array}$ \\
\hline Sex & 1.589 & 1 & 1.589 & 3.883 & 0.050 \\
Class & 0.30 & 1 & 0.030 & 0.073 & 0.787 \\
Error & 123.180 & 3.1 & 0.409 & & \\
Total & 124.803 & 3.3 & & & \\
\hline
\end{tabular}

Referring to the previous table we notice the existence of differences with statistical significance $(\alpha=0.05)$ ascribed to the effect of sex, and referring to the arithmetic on the scale of violence, we find violence behavior appears at males more than females. Also we notice non-existence of differences with statistical significance $(\alpha=$ 0.05 ) ascribed to the effect of class, that means the class has no effect in violence behavior.

The fourth question: is there a connective relationship between the technique of family breeding, and violence behavior at students of the preparatory stage?

The Pierson Connection Coefficient between the technique of family breeding and behavior of violence had been extracted, Table 4 clears that.

Table 4. Pierson connection coefficient of the relationship between the technique of the family breeding and behavior of violence at students of the secondary stage

\begin{tabular}{ccc}
\hline & & Violence Behavior \\
\hline \multirow{2}{*}{ Democratic } & Connection coefficient & 0.11 \\
& Statistical Significance & 0.09 \\
& Number & 3.4 \\
& Connection Coefficient & 0.303 \\
& Statistical Significance & 0.000 \\
& Number & 3.4 \\
& Connection Coefficient & 4.312 \\
& Statistical Significance & 0.000 \\
& Number & 3.4 \\
\hline
\end{tabular}


We notice from Table 4 Non-existence of statistical significant relationship between violence behavior and the democratic technique. Also it was cleared that existence of statistically significant relationship between the behavior of violence and each of the tyrant and lenient techniques.

\section{Discussion of Results}

Results of study indicated by the first question: "what is the level of violence behavior at students of the secondary stage?"

The arithmetic mean of violence behavior amounted (3.81), that indicates that violence behavior at the sample of study came high. And this result shows that students feelings towards other tend to negativeness, and that perhaps be ascribed to their feeling with frustration, and losing self-trust. And their expression of anger appears through numerous behavioral aspects like breaking and aggression. This result is ascribed to the techniques of the tyrant family breeding, followed by parents with sons, and also without concern through the neglected education leads to appearance of violence behavior.

The second question: "what are the techniques of the prevailing family breeding from the point of view of the secondary stage students?

Results of arithmetic means indicated to the techniques of the family breeding that the democratic technique came with the highest arithmetic mean amounted (0.75), and the lenient technique in the second rank at an arithmetic mean amounted (0.26), meanwhile, the tyrant technique came in the last rank and at the lowest arithmetic mean amounted (0.23).

Also this result can be ascribed to students at this stage, stage of adolescence in which the behavior of violence is evident at them. And they express it through leaving the house and searching for troubles and response by nervous movements. Also, individuals' expression of violence differs due to difference of the pattern of family breeding, for the tyrant families use the technique of prevention, rejection, non-discussion and punishment. Results of this question agree with (Coles' study, 2002) whose results indicated to the behavior of violence that connects with the pattern of the negative family breeding, and agrees with (Johns and Jolly, 2005) study, which its results indicated to the tyrant breeding technique, it is the basic cause in the appearance of violence behavior at the sons.

The third question: "are there differences statistically significant at the level of significance $(\alpha=0.05)$ in the level of violence behavior at students of the secondary stage ascribed to both variables of sex and class?"

The results showed the existence of differences ascribed to the effect of sex at the level of violence behavior, and the differences came for the interest of males. This result is ascribed to males, the variable at them is about violence behavior is of more violence and aggressiveness. This in turn affects their interaction with others. Also, it is possible to ascribe this result to the technique of family breeding and the extent of freedom for each of the male and the female, for the males have a space of freedom more than females, also the family education is more strict in collecting females that leads them to non-appearance of violence behavior at them as it is at males.

The fourth question: "is there a connective relationship between the technique of the breeding and violence behavior at students of the secondary stage?".

Results of study disclosed the existence of a positive connective relationship statistically significant between the tyrant technique and the lenient technique and between the violence behavior, meanwhile it was pin-pointed of existence of a negative relationship statistically significant between the behavior of violence and the democratic technique. The family that encourages the independence and the initiative produces individuals who have a positive concept about themselves, and the families that are performed on the tyrant technique, lead to psychological problems and the behavioral disorders like violence, aggressiveness and tendency and disposition. But the technique of the family breeding built on leniency, negligence and non-concern about the sons, may lead them to aspects of behavior socially unaccepted. The present study results agree with results of Al-Ameer study (2004) and (Lopez study,2008), where they both indicated to that the democratic technique, it is that be little's of violence behavior and aggression at sons, meanwhile the tyrant technique and the lenient one both lead to aspects of violence behavior by the individuals.

In light of results of this study the following recommendations can be proposed:

- Concluding training courses for families on techniques of the family breeding.

- Organizing programmes of collective guidance to train students on communication skills. 


\section{References}

Al-Ameer, M. (2010). Patterns of Social Breeding at School and the Family in Jordan and the Relation of that with Studying Excellence (Unpublished). Amman, Jordan.

Al-Rashdan, A. (2015). Social Breeding and Education. Amman, Dar Wael for Publication.

Amer, A. (2014) The Relationship between the Irrational Ideas and Each if Anger, tension and Anxiety at University Students (Unpublished Doctorate Degree Dissertation). Jordan.

Clayton, E., \& Tacker, L. (2010). Anger and Aggression. Psychological Help. New Jersey: Prentice Hall. of the secondary stage.

Coles, C. (2012). The Relationship Between Childrearing, Anger Expression, and perceived Family Control Among Students Self-Concept. Journal of Adolescence, 37(146), 66.

Duriez, B., Soenens, B., \& Vansteenkiste, M. (2015). The Relative Contribution of Parental Goal Promotion and Parenting Style Dimensions. European Journal of Personality, 21, 507-527.

Feshnbach, S. (2011). The Antecedence of Anger, a Developments Approach. Journal of Psychology, 64(2), $160-165$.

Grossman, S. (2011). Understanding Anger in parents of Dying Children. Journal of American Family Physician, 58, 1211-1213.

Hoghughi, M., \& Long, N. (2014). Handbook of Parenting Theory and Research for Practice. Sege Publication, London. Retrieved from http:/members.aol.com/agriesout/grown3.html

Jones, A., \& Jolly, S. (2014) Power in North Carolina Parents: Is There a Relationship Between Family Style and Adolescent Anger. Association Today, 1(2), 207-213.

Liem, H., Cavell, C., \& Lusteg, K. (2010). The Influence of Authoritative Parenting During Adolescence on Depressive Symptoms in Young Adulthood: Examining the Mediating Roles of Self-Development and Peer Support. The Journal of Genetic psychology, 171(1), 73-92.

Lopez, M. (2016). Prevention of Teenage Defiant Behaviors: Parenting Styles as Protection Factors. International Journal of Psychology \& psychological Therapy, 8(1), 73-84.

Namka, L. (2012). Positive Anger Skills: Be a Gentle, Loving Person, You Are Mad.

Naser Allah, O. A. R. (2014). Decline of obtainment level and scholastic accomplishment its causes.

O’beidat, M. (2012). The Relationship Between Patterns of Family Breeding and Effectiveness of oneself (person) at a sample of the Upper Basic Stage Students in Light of some Variables (Unpublished Master Degree Dissertation). Yarmouk University.

Rubin, K., \& Chung. O. (2016). Parenting Beliefs, Behaviors and Parent-Child Relations. New York: Psychology Press.

\section{Copyrights}

Copyright for this article is retained by the author(s), with first publication rights granted to the journal.

This is an open-access article distributed under the terms and conditions of the Creative Commons Attribution license (http://creativecommons.org/licenses/by/4.0/). 